\title{
Cemmetáo
}

\section{Fatores críticos de desenvolvimento em bibliotecas híbridas}

\author{
Rafaela Carolina da Silva \\ Doutoranda; Universidade Estadual Paulista "Júlio de Mesquita Filho", Marília, SP, Brasil; \\ rafaela.c.silva@unesp.br \\ Ieda Pelogia Martins Damian \\ Doutora; Universidade Estadual Paulista “Júlio de Mesquita Filho”, Marília, SP, Brasil; \\ iedapm@usp.br \\ Rosângela Formentini Caldas \\ Doutora; Universidade Estadual Paulista "Júlio de Mesquita Filho", Marília, SP, Brasil; \\ r.caldas@unesp.br
}

Resumo: Ao passo que uma biblioteca converge seus objetivos em benefício do ambiente no qual está inserida, compreende-se que ela está caminhando para se tornar uma biblioteca híbrida. Compreendendo a Gestão do Conhecimento como uma combinação de ideias novas e tradicionais, que envolvem a cultura, as tecnologias, a comunicação e os indivíduos, entende-se que as bibliotecas híbridas trabalham com esse tipo de gestão. Nesse sentido, o objetivo desta pesquisa foi identificar os fatores críticos de sucesso para a Gestão do Conhecimento no ambiente das bibliotecas híbridas. O estudo se caracterizou por ser de natureza qualitativa, do tipo exploratório, precedido por uma revisão da literatura e permeado pelo método Estudo de Caso. Os resultados mostraram que as pessoas, a tecnologia, o compartilhamento do conhecimento e o ambiente são fatores críticos de sucesso necessários para o desenvolvimento da cultura organizacional dessas bibliotecas. Tais fatores podem ser implantados, seguindo as diretrizes de diagnóstico organizacional, análise e concepção do plano de melhoria, encontro interdisciplinar, desenvolvimento da identidade da biblioteca, seleção de equipamentos e tecnologia e implementação e ajuste de serviços. Conclui-se que as variáveis dos fatores críticos de sucesso para a Gestão do Conhecimento em bibliotecas híbridas envolvem o treinamento de usuários, a capacitação dos funcionários, os tipos de tecnologias existentes e sua distribuição para membros e funcionários da biblioteca, as normas de distribuição da informação, a atuação das bibliotecas nas vidas de suas comunidades, as maneiras de desenvolver as comunidades e a integração entre instituições.

Palavras-chave: Bibliotecas híbridas. Fatores críticos de sucesso. Gestão do Conhecimento. 


\section{Introdução}

As bibliotecas, como instituições sociais e culturais, são ambientes de discussão e de apropriação de conhecimento. A memória, nessas instituições, não é só vista como o registro de um grupo social, mas, também, do ambiente que deve ser organizado para obter identidade e ideologia social, formando ideias e agindo sobre elas, dentro de uma esfera cultural no âmbito do desenvolvimento social.

Nessa perspectiva, a missão das bibliotecas vai ao encontro das diferenças culturais do seu público, advindas das variadas esferas sociais, levando em conta suas características econômicas, sociais e sua participação política em sociedade. Nesse sentido, ao passo que uma biblioteca converge seus objetivos em favor do ambiente ao qual está inserida, compreende-se que ela está caminhando para se tornar uma biblioteca híbrida, ou seja, uma instituição na qual o acesso às informações é contextualizado e atualizado para o desenvolvimento social dos indivíduos e de suas comunidades.

Destaca-se que, além da convergência de tecnologias, os elementos participantes do conceito de bibliotecas híbridas são grupos de trabalho, abordagem social, treinamento de usuários, desenvolvimento de softwares inovadores, disponibilização de informação via eletrônica e acesso remoto, onde o elemento mais significativo se caracteriza por ser a abordagem social (SILVA, 2017). Dessa maneira, observa-se que o foco das bibliotecas híbridas está em promover o acesso à informação para que os indivíduos que com elas interagem (funcionários e usuários) sejam capazes de compartilhar e criar conhecimentos úteis para atuar em sociedade, de modo a refletir acerca das informações que recebem e a formar uma rede de compartilhamento de conhecimentos, a partir dos novos conhecimentos adquiridos nessa troca entre sujeitos organizacionais, bem como dos seus conhecimentos prévios.

Nesse contexto, entende-se que, mesmo de forma não institucionalizada, as bibliotecas híbridas trabalham com a Gestão do Conhecimento (GC), compreendida como uma combinação de ideias novas e tradicionais, que envolvem a cultura, as tecnologias, como ferramentas estratégicas no auxílio ao 
desenvolvimento de atividades, a comunicação e os indivíduos, buscando o compartilhamento dos conhecimentos individuais para o coletivo organizacional. Trata-se de compreender como as organizações aplicam o conhecimento, por meio da gestão da informação, em conjunto com os fluxos informacionais e do conhecimento, no desenvolvimento de novos produtos, serviços, processos e arranjos organizacionais, a fim de promover vantagens competitivas sustentáveis (SOUZA; DIAS; NASSIF, 2011).

Levando em consideração que os fatores críticos de sucesso (FCS) para a GC são indispensáveis para o alcance de metas organizacionais, esta pesquisa buscou compreender quais são os FCS presentes, ou passíveis de serem implantados, em bibliotecas híbridas. Logo, o objetivo foi identificar os fatores críticos de sucesso para a GC no ambiente das bibliotecas híbridas, além de propor diretrizes para o desenvolvimento desses fatores nessas localidades.

Para identificar, de forma prática, os FCS em bibliotecas híbridas, a pesquisa contou com um estudo de campo na Biblioteca de São Paulo (BSP) e na Biblioteca Parque Villa-Lobos (BVL). A escolha ocorreu pelo fato de elas serem bibliotecas híbridas que fazem parte do Programa SP Leituras, do Estado de São Paulo, que visa a desenvolver ambientes vivos de leitura e pesquisa, oferecendo coleções atualizadas de livros, revistas, jornais e DVD, em diversos suportes de informação. Também permite acesso à leitura para pessoas com dificuldades de locomoção, visão e/ou audição, além de eventos educativos e culturais, focado na interação com o usuário.

As práticas existentes nessas bibliotecas influenciam no sucesso da implantação da Gestão do Conhecimento, devendo ser analisadas como fatores críticos para o seu sucesso. Entende-se, assim, que o Programa SP Leituras desenvolve bibliotecas híbridas, motivo pelo qual as bibliotecas surgidas a partir desse programa passam a ser objeto de estudo desta pesquisa.

Para tanto, este estudo caracterizou-se por ser de natureza qualitativa, do tipo exploratório, precedido por revisão da literatura sobre os fatores críticos de sucesso para a Gestão do Conhecimento em bibliotecas híbridas. O universo do estudo alcançou as bases de dados Library and Information Science Abstract 
(LISA), Web of Science, Scopus e Base de Dados Referencial de Artigos de Periódico em Ciência da Informação (BRAPCI).

Utilizou-se, na busca, os termos hybrid library AND knowledge management AND critical success factor nas bases de dados internacionais e biblioteca híbrida, gestão do conhecimento e fatores críticos de sucesso na BRAPCI, sem delimitação de tempo, a fim de se recuperar o maior número possível de documentos. Tais bases foram selecionadas por serem projetadas para contemplar, na área da Ciência da Informação, a pesquisa científica em nível nacional e internacional.

Em um segundo momento, o método de Estudo de Caso foi utilizado para entender o universo de pesquisa da BSP e da BVL. Usou-se um roteiro de entrevista semiestruturado, visando coletar informações, opiniões e experiências de profissionais da informação acerca da temática.

\section{Gestão do Conhecimento}

Para Davenport e Prusak (1998), o conhecimento é uma ação efetiva, uma informação contextual, que leva em conta a experiência e o valor de uma cultura, a fim de ser compartilhado, representar e agregar sentido em um contexto. Logo, é uma “[...] mistura fluida de experiência condensada, valores, informação contextual e insight experimentado, a qual proporciona uma estrutura para a avaliação e incorporação de novas experiências e informações." (DAVENPORT; PRUSAK, 1998, p. 6, grifo nosso). Nessa perspectiva, são as pessoas, por meio de suas ações, que geram conhecimento.

No âmbito das organizações, as interações humanas fornecem conhecimento para as suas práticas e processos, fazendo parte do conjunto de valores da instituição. Como destaca Choo (2003), o ciclo do conhecimento nas organizações envolve: a) a criação de significado, que se modifica de acordo com o ambiente onde ele se insere; b) a construção do conhecimento, que preencherá as lacunas necessárias à consecução dos objetivos organizacionais; e c) a tomada de decisões, capacitando a organização para se adaptar aos diferentes contextos de atuação. 
Nesse sentido, para que o conhecimento não fique encapsulado em uma única pessoa, mas possa ser compartilhado do âmbito individual (conhecimento tácito) para o organizacional (conhecimento explícito), é preciso realizar uma administração do conhecimento, isto é, uma Gestão do Conhecimento. De acordo com Barbosa (2008), gerenciar o conhecimento significa planejar e controlar as situações nas quais o conhecimento pode ser produzido, registrado, organizado, compartilhado, disseminado e utilizado, visando possibilitar melhores decisões, acompanhamento de novas tendências e melhoria contínua da organização.

Segundo Souza, Dias e Nassif (2011), a Gestão do Conhecimento busca compreender como as organizações aplicam o conhecimento no desenvolvimento de novos produtos, serviços e processos, de forma a gerir a informação, os fluxos informacionais e o conhecimento de uma organização. Trata-se de um sistema de adaptação a novos arranjos institucionais, que se modifica de acordo com as demandas da cultura organizacional.

Castillo e Cazarini (2009) enfatizam que os três objetivos principais da GC são: a) evitar reinventar a roda, reduzindo a redundância das atividades baseadas em conhecimento; b) auxiliar a organização a inovar o conhecimento continuamente, para que, posteriormente, ele possa ser explorado e criar valor; e c) ajudar no contínuo incremento do nível de competência dos funcionários. Dito isso, a criação do conhecimento organizacional deve ser entendida como um processo que amplificação do conhecimento criado pelos indivíduos, disponível no nível de grupo, por meio de diálogos, discussão e compartilhamento de experiências (NONAKA; TAKEUCHI, 2008).

De acordo com Valentim (2004), as atividades-base da GC são dez. A saber: a) identificação das necessidades e das demandas de conhecimento; b) mapeamento dos fluxos informacionais; c) desenvolvimento de uma cultura organizacional que abarque o compartilhamento e a socialização do conhecimento; d) proporção eficientemente da comunicação da informação, por meio de tecnologias informacionais; e) criação de espaços criativos; f) desenvolvimento de habilidades e de competências de acordo com os objetivos da organização; g) criação de mecanismos para captar o conhecimento gerado 
pelas diferentes pessoas da organização; h) desenvolvimento de sistemas de compartilhamento e uso da informação de diferentes naturezas; i) sistematização do conhecimento por meio de normas e padrões; e j) retroalimentação do ciclo.

Isto posto, Capra (2003, p. 112) acredita que uma abordagem das organizações como "[...] redes não lineares complexas, nos dê novas ideias sobre a natureza da complexidade e nos ajude assim a lidar com as complicações do ambiente empresarial de hoje em dia.”. Portanto, ao se trabalhar com a Gestão do Conhecimento, lida-se com a criação de uma rede de conhecimento, na medida em que se geram ambientes colaborativos para usufruir das condições que cercam a produção e o uso do conhecimento.

\subsection{Fatores críticos de sucesso para a Gestão do Conhecimento}

Os fatores críticos de sucesso podem ser definidos como áreas cujos resultados sejam satisfatórios para garantir o desempenho competitivo e o sucesso das organizações (WONG, 2005). São áreas críticas o planejamento de ações gerenciais que devem ser praticadas para se atingir a eficácia na implementação da GC.

Batista (2014) e Furlanetto e Oliveira (2008) avaliam que os principais FCS para a GC são: a) liderança; b) tecnologia; c) pessoas; d) processos; e) contexto capacitante; f) comunicação e governança; g) alta administração; h) cultura organizacional; i) novas estruturas organizacionais; j) práticas e políticas de GC; k) sistemas de informação; 1) mensuração dos resultados; e m) aprendizagem com o ambiente. Logo, ao se fazer um conglomerado dos fatores críticos citados, pode-se dizer que os fatores-base de desenvolvimento para a GC são: a) pessoas; b) tecnologia; c) compartilhamento de conhecimento; e d) ambiente.

No que se refere às pessoas, entende-se que elas desempenham papel fundamental nos processos de GC, uma vez que são elas que captam, criam, armazenam, compartilham e aplicam o conhecimento. Para tanto, torna-se necessária a promoção de programas de capacitação, educação e desenvolvimento de carreiras, a fim de aumentar a capacidade dos colaboradores 
na execução dos processos de Gestão do Conhecimento, visando à melhoria contínua do desempenho organizacional.

Da mesma maneira, é preciso disseminar informações acerca dos benefícios da política, da estratégia, do plano e das ferramentas de GC na organização, buscando assegurar a participação dos colaborados na sua institucionalização. Assim, uma cultura organizacional favorável à implementação da GC caracteriza-se pela predisposição à exploração e pelo encorajamento à inovação, bem como ao compartilhamento do conhecimento, como forma de multiplicá-lo, reutilizá-lo e valorizá-lo (LIN; TSENG, 2005; WONG, 2005).

Em relação à tecnologia, ela se caracteriza como ferramenta viabilizadora da GC, pois possibilita acelerar os processos de GC, por meio da criação, armazenamento, compartilhamento e aplicação do conhecimento. As principais ferramentas tecnológicas utilizadas na GC são: mecanismos de busca, repositórios digitais, portais, intranet, internet, plataformas de comunidade de práticas virtuais e gestão eletrônica de documentos (GED) (BATISTA, 2014).

O compartilhamento está ligado à comunicação no âmbito organizacional, que deve ser abrangente e sistematizado, por meio de linguagem simples e padronizada, de modo a ser um estímulo permanente ao compartilhamento do conhecimento. Nesse cenário, a constituição de uma estrutura de governança deve ser estabelecida, buscando a constituição de responsabilidades, definidas de acordo com a administração estratégica.

Wong (2005, p. 271) sugere que os processos da Gestão do Conhecimento podem ser "[...] incorporados às atividades diárias dos funcionários, de forma a se tornarem práticas comuns na organização.”. Entende-se que a não integração da GC nos processos rotineiros da organização pode ser um impedimento à sua implementação.

O ambiente abrange as novas estruturas organizacionais, de modo a adequar a organização ao seu contexto de mercado. São considerados aspectos como mudanças internas, cooperação entre equipes, descentralização de tarefas, autonomia, delegação de poder na motivação ao aprendizado, redução de níveis hierárquicos e satisfação dos clientes. 
Davenport e Prusak (1998, p. 56) afirmam que o "[...] conhecimento é invisivelmente criado na mente das pessoas, e somente $\mathrm{o}$ ambiente organizacional adequado a motivará a criá-lo, compartilhá-lo e usá-lo.”. Portanto, trabalha-se com a aprendizagem do ambiente, onde consumidores, fornecedores, parceiros e concorrentes passam a fornecer à instituição condições de ela se apropriar de informações privilegiadas, podendo transformá-las em conhecimento.

\section{Bibliotecas híbridas}

Para contextualizar a trajetória de desenvolvimento e de criação de conceitos acerca das bibliotecas híbridas, é necessário se reportar ao ano de 1992, no Reino Unido, quando as universidades e os cursos politécnicos se separaram, o que impactou no surgimento de novas bibliotecas para a qualidade das pesquisas. Esse assunto foi base para o Joint Funding Consils' Libraries Review Group, que, em novembro de 1993, produziu o Follet Report, um relatório referido ao presidente da comissão, professor Brian Follet, no qual abrangia abordagens de sistemas e redes de infraestrutura para as bibliotecas do Reino Unido, e refletiu na popularização do termo por Chris Rusbridge (INTERNATIONAL..., 2002).

De acordo com Orera Orera e Pacheco (2017), as bibliotecas híbridas se caracterizam por serem novos modelos de estabelecimentos, surgidos na chamada Sociedade da Informação e do Conhecimento, e representam o predomínio das novas tecnologias, a globalização e o volume cada vez maior de informação em formato eletrônico. Para Santa Anna (2015), as bibliotecas híbridas são caracterizadas por disporem de diferentes recursos para viabilizar o armazenamento, o processamento e a disseminação dos documentos gerenciados pela instituição.

Entende-se que elas agregam diferentes tecnologias e fontes de informação, convergindo produtos e serviços que se utilizam de tecnologias como ferramentas estratégicas para unir recursos impressos, bem como digitais.

O papel das bibliotecas híbridas é 
[...] identificar pequenos grupos de usuários e oferecer serviços mais especializados de valor agregado, com grande flexibilidade e criatividade em sua realização e forma, por meio do diagnóstico do que o usuário deseja, realizado de uma forma continuada. (GARCEZ; RADOS, 2002, p. 46).

Logo, segundo Russell, Gardner e Miller (1999), os requisitos básicos dessas bibliotecas são: 1) providência de serviços para descoberta, localização, requisição, envio/entrega e utilização dos recursos; 2) fornecimento de serviços consistente, para recursos locais ou remotos, independentemente do tipo de seu suporte; 3 ) estrutura organizacional flexível, proporcionando o desenvolvimento de novos sistemas quando necessário; e 4) sistemas baseados em normas internacionais, propiciando o aumento do volume e o tráfego de recursos.

Nas bibliotecas híbridas existe "[...] uma maior dialogicidade dos produtos e serviços, uma vez que há uma convergência de mídias tecnológicas e de linguagens." (SILVA; JORENTE; CALDAS, 2017, p. 278). Nesse contexto, os processos tradicionais desempenhados pela biblioteca passam a contar com diversos tipos e formatos de tecnologias informacionais, sendo esses uma complementação das mídias digitais às mídias tradicionais.

Para além da convergência de tecnologias, a biblioteca híbrida deve

[...] ser um espaço cultural, que favoreça a promoção de diálogos, onde indivíduos e tecnologias interagem, a fim de que a informação preservada na biblioteca ganhe vida na medida em que é útil aos usuários e, portanto, usada. (SILVA; CALDAS, 2017, p. 7, tradução nossa $\left.{ }^{1}\right)$.

Dessa maneira, o ambiente dessas bibliotecas é interativo e estimulante, passível de construir uma relação de multiculturalismo de dados, informação e conhecimento, estando o significado de hibridez presente na promoção e no acesso à informação para as diferentes comunidades com quem essas instituições trabalham.

\subsection{Biblioteca de São Paulo e Biblioteca Parque Villa-Lobos}

A BSP e a BVL são bibliotecas públicas híbridas de referência no contexto brasileiro porque o microambiente dessas instituições se contextualiza com a população e com o macroambiente organizacional, o que torna possível a inclusão social, prezada tanto pelos profissionais da informação, quanto pela 
estrutura organizacional local. Além disso, em sua estrutura física, os livros de papel convivem com as novas tecnologias, como e-readers, aparelhos que possibilitam a leitura de livros eletrônicos e outras mídias digitais.

A BSP foi inaugurada em 8 de fevereiro de 2010, com o objetivo de incentivar e promover o gosto pela leitura. Situada na Zona Norte da capital paulista, sua estrutura foi planejada para oferecer conforto, autonomia e atenção aos seus sócios e frequentadores. Ocupa uma área de 4.257 metros, dividindo-se entre o piso térreo e o piso superior, para atender crianças, jovens, adultos e idosos com e sem deficiência. A biblioteca conta com recursos tecnológicos e oferece aos seus usuários microcomputadores, rede wireless e terminal de autoatendimento.

A equipe central da instituição é de 12 funcionários, dividindo-se entre um Diretor de Biblioteca, um Gerente Operacional, um Gerente de Núcleo de Coleções e Tratamento Técnico, um Gerente de Programação e Produção Cultural, um Coordenador de Serviço Social, um Coordenador de Atendimento e seis Líderes de Atendimento. Em 2017, a instituição alcançou uma média de 294.953 usuários frequentadores, 27.514 sócios ativos, 2.617 aquisições, 124.917 consultas e empréstimos e 19.340 participações em ações culturais (BIBLIOTECA..., 2018a).

A BVL, também inaugurada em 2010, ocupa uma área de 4.000 metros quadrados dentro do Parque Villa-Lobos, Zona Oeste de São Paulo. O acervo, constantemente atualizado, tem foco na literatura e um olhar para questões ambientais. É formado por livros, revistas, jornais, livros eletrônicos, audiolivros, HQs, DVDs e CDs, além de livros em braille e falados, voltados para pessoas com deficiência.

Sua equipe central é composta por 12 funcionários, dividindo-se da mesma maneira que na BSP. Em 2017, teve uma média de frequência de 287.026 pessoas, 19.970 sócios ativos, 176.067 consultas e empréstimos e 22.054 participações em ações culturais (BIBLIOTECA..., 2018b).

A BSP e a BVL desenvolvem um conjunto de iniciativas com a Secretaria de Estado da Cultura de São Paulo para incentivar e promover o gosto pela leitura, que se dá tanto pelo livro tradicional, como pelo digital. O conceito 
de hibridez, aplicado nessas instituições, contribuiu para o desenvolvimento de um sistema de gerenciamento da informação, que controla todas as rotinas das bibliotecas, propiciando ao leitor a retirada de títulos de seu interesse, sem usar o atendimento do balcão. Ao mesmo tempo, a hibridez as torna um lugar de entretenimento familiar e de readaptação social, capacitando toda a comunidade que as cerca, independentemente de gênero, idade, situação econômica ou instrução social.

Como Silva (2017) destaca, a hibridez, nessas localidades, ocorre por meio: a) de práticas internacionais (possuem parceria com a Biblioteca de Santiago, Chile); b) da sintonia com as ações governamentais do Brasil; c) dos espaços arrojados, possuindo projeto inovador de inclusão social por meio da leitura (a estrutura de ambas as instituições foi planejada para oferecer conforto, autonomia e atenção aos sócios e frequentadores, que são o elemento central da biblioteca); d) da revitalização dos prédios (antes antiga Casa de Detenção Carandiru, na BSP); e) das informações disponíveis em variados tipos de suporte e mídia (oferecem conteúdos em formatos variados, em livros tradicionais ou em formatos acessíveis, como braille, audiolivro, Kindles, DVDs, CDs, além de jogos); f) da ambientação, que oferece ao público um espaço acolhedor, como convite à leitura; g) da sociedade, que pode contribuir na escolha de itens a serem adquiridos para o acervo; h) dos acervos atualizados frequentemente (o grande foco são a literatura nacional e a internacional, sendo os assuntos complementares das áreas de Filosofia, Religião, Autoajuda, Esportes, Biografias, História, entre outras).

Ainda, essas bibliotecas caracterizam-se como laboratórios de práticas da área de Biblioteconomia e Ciência da Informação, sediando, permanentemente, cursos e eventos organizados pelo Sistema Estadual de Bibliotecas Públicas (SisEB), voltados para a capacitação das equipes das bibliotecas públicas municipais, integrantes do sistema. Além disso, tais instituições trabalham com uma equipe diferenciada para atender às necessidades dos usuários e recebem outros equipamentos culturais que desenvolvem atividades em seu espaço físico, como é o caso do Ponto MIS, desenvolvido pelo Museu da Imagem e do Som 
(MIS), um projeto que promove o audiovisual e a formação de plateias, por meio de parcerias com instituições públicas do Estado de São Paulo.

\section{Metodologia}

Esta pesquisa teve cunho exploratório e qualitativo. Em um primeiro momento, foi feita uma revisão da literatura nas bases de dados LISA, Web of Science, Scopus e BRAPCI acerca dos fatores críticos de sucesso para a Gestão do Conhecimento em bibliotecas híbridas. Tais bases foram selecionadas por contemplarem a área da Ciência da Informação em nível nacional e internacional.

Nas bases de dados internacionais, os mecanismos de busca usados foram as palavras-chave hybrid library, como assunto principal, bem como knowledge management e critical success factors, como assuntos secundários. Na BRAPCI, os termos foram digitados em português: biblioteca híbrida, gestão do conhecimento e fatores críticos de sucesso.

Ressalta-se que não houve delimitação de tempo, já que o intuito era recuperar o maior número de literatura possível sobre o assunto. Para complementar o estudo prático, demonstrado a seguir, o levantamento bibliográfico foi realizado em setembro de 2018, buscando atualizar as informações já estabelecidas no ano de 2016.

Em um segundo momento, o método de Estudo de Caso foi utilizado para entender o universo de pesquisa da BSP e da BVL. Usou-se um roteiro de entrevista semiestruturado, o qual teve como objetivo coletar informações, opiniões e experiências dos profissionais dessas localidades. A coleta de dados efetivou-se por meio de entrevistas com as bibliotecárias-chefe, com os coordenadores dos setores de Atendimento, de Marketing e de Programação, assim como com a Assistência Social de cada instituição.

O Setor de Atendimento realizou uma visita guiada pelas bibliotecas, explicando cada espaço e suas utilidades. A Assistência de Diretoria contribuiu durante a visita, delimitando tempo e espaços a observar. Por meio da entrevista à Assistência Social, foi possível ter uma visão ampla da abordagem 
sociocultural da BSP e da BVL, seus produtos, serviços e ações de inclusão social. O Setor de Bibliotecários, além de explicar o funcionamento da biblioteca, trouxe dois aportes teóricos para a pesquisa: o conceito de usuários como sócios da instituição (usuários como protagonistas dentro do espaço da biblioteca), bem como o de Gestão do Conhecimento em bibliotecas híbridas.

A entrevista contou com sete questões. Cada pergunta relacionou-se com um dos fatores críticos de sucesso identificados na literatura. As entrevistas foram realizadas durante o mês de junho de 2016, contemplando 1) formas treinamento de usuários; 2) formas capacitação de funcionários; 3) tipos de tecnologias existentes e distribuição das mesmas para membros ou funcionários da biblioteca; 4) formas de distribuição da informação; 5) atuação das bibliotecas nas vidas de suas comunidades; 6) maneiras de desenvolver as comunidades; e 7) integração entre instituições.

Os dados coletados foram estruturados em uma análise única, onde as informações fornecidas por respondente complementaram-se nas respostas das questões apreendidas pela entrevista. A escolha por tais localidades se fundamentou no fato de elas fazerem parte do Programa SP Leituras, contribuindo na identificação de fatores nacionais estratégicos para a atuação de bibliotecas.

As informações obtidas por meio das entrevistas foram analisadas e comparadas aos fatores e variáveis elencados na pesquisa, considerados estratégicos para a Gestão do Conhecimento em bibliotecas híbridas. Os resultados estão apresentados de forma narrativa e contextualizada, servindo de base para o desenvolvimento da fase de discussões deste artigo.

\section{Resultados e discussões}

Na primeira etapa da pesquisa, ou seja, no levantamento bibliográfico realizado nas bases de dados LISA, Web of Science e Scopus, não foi recuperado nenhum resultado, o que demonstra a carência de estudos, em âmbito internacional, sobre os fatores críticos de sucesso para a Gestão do Conhecimento em bibliotecas híbridas. Na BRAPCI, foram recuperados dois artigos, apenas. 
O primeiro artigo foi o de Suaiden e Araújo Júnior (2001), que trata da técnica do benchmarking como estratégia de sucesso em bibliotecas públicas. Os autores identificaram os seguintes FCS para a GC, que podem ser aplicados em bibliotecas híbridas: a) qualidade do atendimento às demandas dos usuários e da comunidade (aspectos relacionados à exigência dos usuários/comunidade em termos de produtos e serviços e à resposta da biblioteca em termos de nível de satisfação desses usuários/comunidade); b) disponibilização de um serviço de informação à comunidade (serviços oferecidos gratuitamente ao cidadão, a fim de satisfazer suas necessidades informacionais quanto aos órgãos públicos e privados, de modo a permitir a sua efetiva participação na vida da comunidade e do país); e c) realização de um diagnóstico das necessidades de informação dos usuários/comunidade (planejamento do atendimento da biblioteca, realizando um diagnóstico para identificar os ajustes e as mudanças a serem implementados, visando a melhoria contínua no atendimento de demandas).

O segundo estudo localizado foi o de Marchiori (2012), que trabalha com as bibliotecas digitais e com os repositórios de objetos de aprendizagem. Para a autora, as articulações fornecidas pelas bibliotecas digitais e pelos repositórios, com as comunidades de interesse (usuários, curadores e gestores), são os elementos críticos para o sucesso do uso de repositórios como objetos de aprendizagem.

Traçando um paralelo com as questões aplicadas no estudo prático desta pesquisa, isto é, com as entrevistas efetuadas na BSP e na BVL, entende-se que o fator qualidade do atendimento às demandas dos usuários e da comunidade (SUAIDEN; ARAÚJO JÚNIOR, 2001) se relaciona com a questão 2 da entrevista - capacitação de funcionários, bem como com a 3 - tipos de tecnologias existentes. O fator disponibilização de um serviço de informação à comunidade (SUAIDEN; ARAÚJO JÚNIOR, 2001) se refere às questões 4 formas de distribuição da informação e 5 - atuação na vida das comunidades e 6 - desenvolvimento de comunidades.

O fator realização de um diagnóstico das necessidades de informação dos usuários/comunidade (SUAIDEN; ARAÚJO JÚNIOR, 2001) está diretamente ligado com a questão 1 - treinamento de usuários. Já o fator articulação das 
atividades com as comunidades de interesse (MARCHIORI, 2012), com a questão 7 - integração entre instituições.

As respostas às questões das entrevistas destacaram que o treinamento de usuários é promovido na sua ambientação ao ambiente da biblioteca. Tal ambientação ocorre por meio de atualizações, reuniões coletivas ou individuais, assim como pela reciclagem dos treinamentos a cada seis meses.

Para a capacitação dos funcionários é realizada uma ambientação de três meses em cada setor da biblioteca, a fim de que eles conheçam a gestão, os softwares existentes, o serviço social, a pesquisa, a lógica, a programação e a administração do local. As atualizações vão ocorrendo de acordo com as necessidades de adaptação de cada funcionário e, no fim do terceiro trimestre de cada ano, é feita uma reciclagem.

Os tipos de tecnologias existentes abarcam o acesso remoto, onde as bibliotecas propiciam que o usuário renove um item informacional pelo site das instituições ou pelo telefone. A informação via eletrônica pode ser acessada pelo site institucional e por meio das redes sociais, que possuem informações acerca das políticas e das atividades das bibliotecas. Em relação aos softwares inovadores, a novidade está relacionada aos softwares de negócios e de acessibilidade, buscando a inclusão de deficientes auditivos, visuais e físicos.

No item formas distribuição da informação, o acervo é caracterizado por obras de referência, revistas, periódicos, CDs e DVDs que retratam, especialmente, a literatura brasileira e a sustentabilidade, independentemente do tipo de suporte. Há também a divisão por faixas etárias, caso da Área +60 (voltada para o convívio de idosos que, em sua maioria, preferem o silêncio à interação social).

A atuação na vida das comunidades é destacada pela mediação da leitura, que acontece de acordo com as atividades culturais desenvolvidas pelas bibliotecas, como também pelas ações educativas, convidando grupos de pessoas a participar das ações sociais promovidas pela assistência social, e sugerindo questões de cidadania, que podem ser discutidas individualmente ou em grupo. As pautas sempre falam da realidade do público e da sua relação com a biblioteca, a fim de esclarecer dúvidas e desenvolver projetos de acolhimento. 
O desenvolvimento de comunidades é percebido no fato de a assistência social local trabalhar com a comunidade no sentido de entender as necessidades básicas que não foram supridas, sejam elas de âmbito social (fome, higiene, falta de moradia), psicológico ou psiquiátrico, tratando da integridade física do usuário, para que ele se torne sócio da biblioteca. Trata-se de um processo de reabilitação, feito em conjunto com o Estado de São Paulo, de orientação aos usuários no sentido de suprir suas necessidades básicas e informacionais. Logo, a intermediação é feita para que eles entendam o que é o espaço da biblioteca e passem a usá-lo de maneira harmoniosa e produtiva.

O reconhecimento do entorno ocorre em visitas a escolas, creches, espaços para idosos, centros de acolhida, enfim, na medida em que fazem parcerias com as comunidades mais distantes, para que o público e as instituições saibam da existência da BSP e da BVL, suas propostas de trabalho, oferecimento de oficinas e atividades culturais. Tal ação propicia às pessoas o interesse pelo trabalho das instituições e, consequentemente, a inclusão social.

A integração com outras bibliotecas é vista na participação dessas duas instituições no Programa SP Leituras, bem como com outras localidades, como o Museu da Língua Portuguesa, escolas técnicas estaduais, artistas locais, além de escritores, músicos e profissionais que promovem ações de desenvolvimento intelectual e humano dessas pessoas. Ademais, os sites dessas localidades disponibilizam livros eletrônicos gratuitos e acesso ao catálogo de outras bibliotecas virtuais, a saber: Biblioteca Digital Mundial, Biblioteca do Congresso dos Estados Unidos da América, ebooksBrasil, Enciclopédia Britânica, SciELO Livros, Biblioteca Virtual da América Latina, Biblioteca Virtual do Governo do Estado, Biblioteca Brasiliana Guita e José Mindlin, Children's Library e Dorinateca - Biblioteca Digital Dorina Nowill.

Percebe-se, assim, o estreito relacionamento entre as práticas identificadas pelos respondentes das bibliotecas analisadas, a visão estratégica da Gestão do Conhecimento e os fatores e variáveis identificados na literatura. Como mostra o Quadro 1, ao relacionar as respostas das questões das entrevistas com os itens abarcados pela literatura, os fatores críticos de sucesso para a Gestão do Conhecimento em bibliotecas híbridas, mais especificamente nos 
cenários da BSP e da BVL, podem ser identificados da seguinte maneira: a) formas treinamento de usuários (fator crítico 'pessoas'); b) formas capacitação de funcionários (fator crítico 'pessoas'); c) tipos de tecnologias existentes na instituição e distribuição entre membros ou funcionários da biblioteca (fator crítico 'tecnologia'); d) formas de distribuição da informação (fator crítico 'compartilhamento de conhecimento'); e) atuação das bibliotecas nas vidas de suas comunidades (fator crítico 'ambiente'); f) maneiras de desenvolver as comunidades (fator crítico 'ambiente'); e g) integração entre instituições (fator crítico 'compartilhamento de conhecimento').

Quadro 1 - Fatores críticos de sucesso para a implementação da Gestão do Conhecimento em bibliotecas híbridas

\begin{tabular}{|c|c|}
\hline Fatores & Variáveis \\
\hline Pessoas & $\begin{array}{l}\text { - Treinamento de usuários: } \\
\text { - Ambientação; } \\
\text { - Atualizações; } \\
\text { - Reuniões coletivas ou individuais; } \\
\text { - Reciclagem. } \\
\text { - Capacitação dos funcionários: } \\
\text { - Ambientação; } \\
\text { - Atualizações; } \\
\text { - Reciclagem. }\end{array}$ \\
\hline Tecnologia & $\begin{array}{l}\text { - Tipos de tecnologias existentes e sua distribuição para } \\
\text { membros e funcionários da biblioteca: } \\
\text { - acesso remoto; } \\
\text { - informação via eletrônica; } \\
\text { - Softwares inovadores. }\end{array}$ \\
\hline $\begin{array}{l}\text { Compartilhamento } \\
\text { de conhecimento }\end{array}$ & $\begin{array}{l}\text { - Formas de distribuição da informação: } \\
\text { - Obras de referência; } \\
\text { - Revistas; } \\
\text { - Periódicos; } \\
\text { - CDs; } \\
\text { - DVDs; } \\
\text { - Divisão por faixas etárias. } \\
\text { - Integração entre instituições: } \\
\text { - Programas municipais e estaduais; } \\
\text { - Museus e galerias; } \\
\text { - Escolas; } \\
\text { - Artistas; } \\
\text { - Escritores; } \\
\text { - Músicos; } \\
\text { - Bibliotecas nacionais e estrangeiras. }\end{array}$ \\
\hline
\end{tabular}




\begin{tabular}{|c|c|}
\hline Ambiente & $\begin{array}{l}\text { - Atuação das bibliotecas nas vidas de suas comunidades: } \\
\text { - Mediação da leitura; } \\
\text { - Atividades culturais; } \\
\text { - Ações educativas; } \\
\text { - Ações sociais. } \\
\text { - Maneiras de desenvolver as comunidades: } \\
\text { - Processo de reabilitação; } \\
\text { - Orientação aos usuários; } \\
\text { - Suprimento de necessidades básicas e } \\
\text { - informacionais; } \\
\text { - Parcerias com comunidades mais distantes; } \\
\text { Oferecimento de oficinas e atividades culturais. }\end{array}$ \\
\hline
\end{tabular}
Fonte: Elaborado pelos autores.

No que se refere ao FCS pessoas, o item treinamento de usuários trata das maneiras que a biblioteca utiliza para integrar os usuários aos serviços oferecidos pela instituição: capacitação, plantão de dúvidas, atualização, workshops, oficinas, palestras e atendimentos em grupo ou individuais. Em relação à capacitação dos funcionários, entende-se o desenvolvimento de workshops que busquem solucionar barreiras existentes, delimitação de espaços de aprendizagem, treinamento e desenvolvimento pessoal, além da educação continuada.

Para as tecnologias existentes, o índice de acesso remoto se refere às formas de renovação de itens emprestados (por internet, pelo telefone), às formas de empréstimos de recursos (online, via telefone, pessoalmente) e aos processos de digitalização do acervo analógico. A informação via eletrônica se refere aos suportes informacionais existentes (bases de dados online, e-books) e disponibilizados pelas bibliotecas, à promoção de informações institucionais em sites e em redes sociais e ao desenvolvimento de bibliotecas virtuais.

No compartilhamento, há o gerenciamento de dados, da informação e do conhecimento pela biblioteca, as formas de acessibilidade para pessoas com deficiência, as maneiras de as bibliotecas entreterem a população e as atividades lúdicas proporcionadas pelas estruturas de cada localidade. Trata-se da promoção de diálogos com os usuários, visando suprir problemas de integridade física, além da realização do reconhecimento do entorno da biblioteca, trabalhando com a mediação da leitura, por meio de atividades de contação de 
histórias, discussões filosóficas, oferecimentos de cursos de escrita e redação, oficinas culturais, dentre outros.

O ambiente da organização propicia a abordagem sociocultural, ou seja, o acolhimento do usuário pela biblioteca e a sua ressocialização. Na mesma linha de pensamento, têm-se os grupos de trabalho, ligados à divisão de atividades por categorias (infantil, infanto-juvenil, jovens, adultos, idosos) e à participação de outras instituições no desenvolvimento dos programas das organizações (parcerias entre empresas públicas e privadas e a biblioteca).

Dito isso, destaca-se que as informações obtidas nas entrevistas confirmaram os fatores estratégicos identificados na literatura. Pode-se entender que, no âmbito geral das bibliotecas híbridas, as pessoas, a tecnologia, o compartilhamento do conhecimento e o ambiente são elementos necessários para o desenvolvimento da cultura organizacional dessas bibliotecas, bem como para a implantação de novas estruturas organizacionais, já que fazem parte dos investimentos em tecnologias da informação, das práticas e das políticas da gestão de pessoas, da orientação para os processos e da mensuração de resultados, sendo diretamente influenciados pelas decisões da alta administração (bibliotecários-chefe) que, por sua vez, influem nas decisões adotadas.

A prática em bibliotecas híbridas indica que a existência dos fatores estratégicos é indispensável ao desenvolvimento de projetos de gestão do conhecimento. Assim, infere-se que os fatores críticos de sucesso delimitados por este estudo (pessoas, tecnologias, compartilhamento de conhecimento e ambiente) influenciam significativamente no sucesso dessas organizações.

Nesse contexto, entende-se que, para a efetiva implementação da Gestão do Conhecimento em bibliotecas híbridas, é necessário seguir algumas diretrizes, propostas como resultado desta pesquisa. Tais diretrizes são formadas pelos seguintes elementos:

- Diretriz 1 - Diagnóstico organizacional: estudo de necessidades informacionais; medição da satisfação dos usuários; análise da capacidade e flexibilidade das equipes de funcionários; análise da organização técnica e automação da coleção; condições ambientais. 
- Diretriz 2 - Análise e concepção do plano de melhoria: seleção e aplicação de normas internacionais para bibliotecas; modelamento da arquitetura e do projeto da biblioteca em software específico para esta finalidade.

- Diretriz 3 - Encontro interdisciplinar: coerência nas ações administrativas e nas metas da instituição; apoio a recompensas; cultura organizacional; relações internas e externas; e fluxo de conhecimento entre equipes.

- Diretriz 4 - Desenvolvimento da identidade da biblioteca: tabela de capacidades (recursos físicos, financeiros, humanos e cognitivos).

- Diretriz 5 - Seleção de equipamentos e tecnologia: salas de leitura formal e informal; salas de estudo particulares e coletivas; estantes; mesas e cadeiras; lousas; controle de acesso; reprografia; segurança; sinalização; serviços complementares; automação hipertextual; acervo digital; software de automação de bibliotecas; audiolivros; tablets; livros digitais; código de barras.

- Diretriz 6 - Implementação e ajuste de serviços: práticas e políticas de gestão de pessoas; programas de capacitação, de acordo com os objetivos da organização; aproximação entre os níveis hierárquicos.

\section{Considerações finais}

As vivências das bibliotecárias-chefe, dos coordenadores dos setores de Atendimento, de Marketing e de Programação, assim como da Assistência Social da BSP e da BVL, reforçaram os fatores críticos de sucesso para a Gestão do Conhecimento em bibliotecas híbridas identificados na literatura, destacando as vantagens competitivas decorrentes de processos sistematizados para a geração, compartilhamento, disseminação e registro de conhecimentos. Embora haja poucos estudos sobre a temática no âmbito da Ciência da Informação, o que delimita esta pesquisa, importante destacar, é que os fatores críticos de sucesso levantados, especificamente para as bibliotecas híbridas, relacionam-se com os delimitados pelos autores clássicos do campo da Gestão do Conhecimento. 
A interface com as comunidades das bibliotecas estudadas traz um arcabouço teórico para essas instituições, uma vez que permite que elas passem a agregar conhecimentos úteis para atuar diretamente nas necessidades e desejos informacionais de seus usuários. Tais práticas, quando aplicadas em bibliotecas híbridas, permitem a mensuração de resultados, necessária à melhoria contínua dessas organizações.

Entende-se que a Gestão do Conhecimento é estratégica, por assegurar a geração e a disseminação do conhecimento, otimizando a utilização e a reutilização de recursos de conhecimento, sendo a mensuração de resultados necessária à percepção das ações das organizações em suas comunidades. Os funcionários e usuários são motivados quando percebem que a biblioteca investe no seu conhecimento, por meio da aprendizagem com o ambiente, que é dinâmico e flexível.

As variáveis dos FCS para a GC em bibliotecas híbridas envolvem o treinamento de usuários, a capacitação dos funcionários, os tipos de tecnologias existentes e sua distribuição para membros e funcionários da biblioteca, as normas de distribuição da informação, a atuação das bibliotecas nas vidas de suas comunidades, as maneiras de desenvolver as comunidades e a integração entre instituições. Ressalta-se que o uso de tecnologias não assegura a implantação da gestão do conhecimento, mas viabiliza as ações nesse sentido.

Nesse cenário, as bibliotecas híbridas são localidades que aprendem com o ambiente, adequando-se ao espaço dinâmico presente na sociedade moderna. Dessa maneira, os fatores críticos de sucesso para a Gestão do Conhecimento atuam de forma integrada com a cultura organizacional dessas localidades.

Sugere-se, para estudos futuros, a análise dos fatores elencados em bibliotecas híbridas, em forma de estudo prático, para o contexto internacional, visando desenvolver novos instrumentos de implantação de Gestão do Conhecimento. Nesse sentido, um estudo mais amplo de identificação dos fatores críticos de sucesso para a Gestão do Conhecimento em bibliotecas híbridas permitiria uma visão sistemática de atuação em cenários não delimitados, como o ocorrido nesta pesquisa. 


\section{Financiamento}

Fundação de Amparo à Pesquisa do Estado de São Paulo (FAPESP).

\section{Referências}

BARBOSA, R. R. Gestão da informação e do conhecimento: origens, polêmicas e perspectivas. Informação \& Informação, Londrina, v. 13, n. esp., p. 1-25, 2008.

BATISTA, F. F. et al. Casos reais de implantação do modelo de gestão do conhecimento para a administração pública brasileira. Brasília; Rio de Janeiro: Instituto de Pesquisa Econômica Aplicada (IPEA), 2014.

BIBLIOTECA DE SÃO PAULO. 2018a. Disponível em: https://bsp.org.br. Acesso em: 17 set. 2018.

BIBLIOTECA PARQUE VILLA-LOBOS. 2018b. Disponível em: https://bvl.org.br. Acesso em: 17 set. 2018.

CAPRA, F. As conexões ocultas: fundamentos para uma vida sustentável. São Paulo: Cultrix, 2003.

CASTILLO, L. A. M.; CAZARINI, E. W. Modelo integrado para a implantação da gestão do conhecimento. Revista GEPROS: Gestão da produção, Operações e Sistemas, Bauru, ano 4, n. 4, p. 61-77, out./dez. 2009.

CHOO, C. W. A organização do conhecimento: como as organizações usam a informação para criar significado, construir conhecimento e tomar decisões. São Paulo: Senac, 2003.

DAVENPORT, T. H.; PRUSAK, L. Conhecimento empresarial. Rio de Janeiro: Campus, 1998.

FURLANETTO, A.; OLIVEIRA, M. Fatores estratégicos associados às práticas de gestão do conhecimento. Análise, Porto Alegre, v. 19, n. 1, p. 99-123, jan./jun. 2008.

GARCEZ, E. M. S.; RADOS, G. J. V. Biblioteca híbrida: um novo enfoque no suporte à educação a distância. Ciência da Informação, Brasília, v. 31, n. 2, 2002.

INTERNATIONAL FEDERATION OF LIBRARY ASSOCIATIONS AND INSTITUTIONS. Libraries in the information society. München: Saur, 2002.

. LIN, C.; TSENG, S. M. The implementation gaps for the knowledge management system. Industrial Management \& Data Systems, [s.l], v. 105, n. 2, pp. 208-222, 2005. 
MARCHIORI, P. C. Z. Bibliotecas digitais e repositórios de objetos de aprendizagem. Informação \& Sociedade: Estudos, João Pessoa, v. 22, n. 2, p. 13-21, 2012.

NONAKA, I.; TAKEUCHI H. Gestão do Conhecimento. Porto Alegre: Bookman, 2008.

ORERA ORERA, L.; PACHECO, F. H. El desarrollo de coleciones em bibliotecas públicas: fundamentos teóricos. Investigación Bibliotecológica, Ciudad de México, v. 31, n. 71, 2017.

RUSSELL, R.; GARDNER, T.; MILLER, P. Hybrid information environments: overview and requirements. 1999. Disponível em: http://www.ukoln.ac.uk/dlis/models/requirements/overview/. Acesso em: 20 jan. 2018 .

SANTA ANNA, J. A oferta diversificada de produtos e serviços bibliotecários na contemporaneidade: a biblioteca híbrida em evidência. Revista Brasileira de Biblioteconomia e Documentação, São Paulo, v. 11, n. especial, p. 275-294, 2015.

SILVA, R. C.; CALDAS, R. F. Las bibliotecas públicas híbridas en el contexto brasileño. Palabra Clave, Chía, v. 6, n. 2, 2017.

SILVA, R. C. Gestão de bibliotecas públicas no contexto híbrido: um estudo comparativo de bibliotecas híbridas no âmbito nacional e internacional em prol do desenvolvimento de comunidades. 2017. Dissertação (Mestrado em Ciência da Informação) - Faculdade de Filosofia e Ciências, Universidade Estadual Paulista "Júlio de Mesquita Filho", Marília, 2017.

SILVA, R. C.; JORENTE, M. J. V.; CALDAS, R. F. Integração da competência em informação no contexto das bibliotecas vivas. RICI: Revista IberoAmericana de Ciência da Informação, Brasília, v. 10, n. 2, p. 275-294, jul./dez. 2017.

SOUZA, E. D.; DIAS, E. J. W.; NASSIF, M. E. A gestão da informação e do conhecimento na Ciência da Informação: perspectivas teóricas e práticas organizacionais. Informação \& Sociedade: Estudos, João Pessoa, v. 21, n. 1, p. 55-70, jan./abr. 2011.

SUAIDEN, E. J.; ARAÚJO JÚNIOR, R. R. H. Biblioteca pública e a excelência nos produtos e serviços: a técnica do benchmarking. Informação \& Sociedade: Estudos, João Pessoa, v. 11, n. 1, p. 1-13, 2001. 


\title{
VALENTIM, M. L. P. Gestão da informação e gestão do conhecimento:
} especificidades e convergências. Londrina: Infohome, 2004.

WONG, Y. K. Critical success factors for implementing knowledge management in small and medium enterprises. Industrial Management \& Data Systems, [s.l], v. 105, n. 3, p. 261-279, 2005.

\section{Critical development factors in hybrid libraries}

\begin{abstract}
When a library converges it goals to the environment in which it is inserted, it is understood that it is moving to be hybrid. Understanding Knowledge Management as a mix of new and traditional ideas, which involves culture, technology, communication and individuals, hybrid libraries work with it. From this perspective, this research aims to identify the critical success factors for Knowledge Management in hybrid library's environment. The study has qualitative approach, and exploratory type, preceded by a literature review, and permeated by the Case Study method. The results showed people, technology, knowledge sharing, and environment are critical success factors for the development of organizational culture in hybrid libraries. These factors can be implemented following organizational diagnosis guidelines, improvement plan, interdisciplinary meeting, library identify, selection of technology, and implement/adjustment of services. It concludes the critical success factors for Knowledge Management in hybrid libraries involve user training, employee training, types of existing technologies and their distribution to library members and employees, libraries in the lives of their communities, ways of developing communities, and integration between institutions.
\end{abstract}

Keywords: Hybrid libraries. Critical success factors. Knowledge Management.

Recebido: 02/07/2019

Aceito: $21 / 10 / 2019$

\footnotetext{
${ }^{1}$ No original: “[...] ser un espacio cultural que favorezca la promoción de diálogos, donde la población y las tecnologías interactúen, de forma que las informaciones preservadas en la institución pasen a ganar vida en la medida en que estas son utilizadas.".
} 